\title{
Tarif Pelayanan Pandu Pada PT. Pelindo IV (Persero) Cabang Parepare
}

\author{
Rahmawati Djunuda*1, Syamsul Asri ${ }^{1}$, Andi Sitti Chairunnisa Mappangara ${ }^{1}$ \\ ${ }^{1}$ Departemen Teknik Perkapalan, Fakultas Teknik, Universitas Hasanuddin \\ Jl. Poros Malino km. 6 Bontomarannu, Gowa, Sulawesi Selatan \\ *E-mail: rahma_limola@yahoo.co.id
}

DOI: 10.25042/jpe.052017.12

\begin{abstract}
Abstrak
Jasa pemanduan diberikan sewaktu kapal memasuki alur pelayaran menuju dermaga untuk menjaga keselamatan kapal dan muatannya ketika memasuki alur pelabuhan. Penelitian ini bertujuan untuk mengetahui kelayakan tarif pelayanan pandu di pelabuhan Parepare jika ditinjau dari sisi operator. Data dianalisis dengan metode RFR (Requered Freight Rate). Hasil penelitian menunjukkan bahwa tarif variabel pelayanan pandu yang berlaku sekarang sudah layak. Dari hasil perhitungan didapatkan tarif minimal yaitu Rp. 8,38 per GT/gerakan lebih kecil dari tarif yang berlaku sekarang yaitu Rp. 76,78 per GT/gerakan. Ini berarti bahwa tarif yang berlaku sekarang sudah mampu menutupi biaya operasional. Sedangkan tarif tetap pelayanan pandu yang berlaku dianggap belum layak. Karena dari hasil perhitungan diperoleh tarif minimal Rp. 251.797 per gerakan lebih besar dari tarif yang berlaku sekarang yaitu Rp. 175.175 per gerakan, yang berarti bahwa tarif tetap yang berlaku sekarang belum mampu menutupi biaya operasional. Tarif ini bisa dinaikkan oleh pihak operator dengan lebih meningkatkan pelayanan kepada pengguna jasa.
\end{abstract}

\begin{abstract}
Scout Service Tariff of PT. Pelindo IV (Persero) Parepare Branch. The scout the service is given when a ship enters the cruise line to a pier to maintain the ship safety and its cargo when it enters the port line. The research aimed at investigating the feasibility of the scout service tariff in Parepare port a viewed from the operator side. Data were analysed using the RFR (Requiered Freight Rate) method. The research result indicates that the tariff variable of the scout service that is valid now has been feasible. The calculation result is obtained the minimal tariff of Rp 8,38 GT/movement, smaller than the tariff that is valid at the moment namely Rp 76,78 GT/movement. This means that the tariff being valid now has been able to cover the operational expenditure. Whereas the valid permanent tariff of the scout service is assumed not to be feasible because the calculation result obtained the minimal tariff of Rp 251.797 /movement, bigger than the tariff that is valid now namely Rp 175.175 /movement, which means that the permanent tariff being valid at the moment has not been able to cover the operational axpenditure. The tariff can be increased by the operator side by increasing the service quality to the service users.
\end{abstract}

Kata-kunci: Frekuensi, GT, RFR, tarif

\section{Pendahuluan}

Pelabuhan mempunyai peran penting dan strategis untuk pertumbuhan industri dan perdagangan serta dapat memberikan kontribusi bagi pembangunan nasional. Hal ini membawa konsekuensi terhadap pengelolaan segmen usaha pelabuhan agar pengoperasiannya dapat dilakukan secara efektif, efisien dan profesional sehingga pelayanan pelabuhan menjadi lancar, aman, dan cepat dengan biaya yang terjangkau [1].

Pelabuhan Parepare sebagai pelabuhan pengumpul sangat mendukung pusat kegiatan regional dan daerah yang berpotensi untuk berkembang dengan cepat [2]. Adapun fasilitas pokok pelabuhan terdiri dari alur pelayaran, kolam pelabuhan, serta dermaga. Sedangkan fasilitas penunjang diantaranya lapangan penumpukan untuk petikemas, terminal dan jalan untuk memperlancar perpindahan kendaraan di pelabuhan.

Pelayanan jasa pelabuhan Parepare antara lain pelayanan jasa kapal, barang, dan penumpang. Untuk pelayan jasa kapal terdiri atas jasa pandu, jasa tunda, jasa tambat dan jasa air. Jasa kepelabuhanan memiliki peranan masingmasing dan memiliki keterkaitan satu dengan lainnya demi menunjang kelancaran aktifitas 
kapal dalam kegiatannya mendistribusikan barang [3].

Menurut PM 57 tahun 2015 pasal 28 tentang Pemanduan dan Penundaan Kapal bahwa pada perairan yang ditetapkan sebagai peraiaran wajib pandu, kapal berukuran tonase kotor paling rendah GT 500 atau lebih wajib menggunakan pelayanan jasa pemanduan kapal. Dan kapal yang berukuran tonase kurang dari GT 500 pelayanan pemanduan diberikan pada kapal atas permintaan Nakhoda atau atas perintah pengawas pemanduan setempat.

Jasa pemanduan diberikan sewaktu kapal memasuki alur pelayaran menuju dermaga untuk menjaga keselamatan kapal dan muatannya ketika memasuki alur pelabuhan. Pemanduan memberikan bantuan kepada Nakhoda kapal agar navigasi saat melewati alur atau daerah wajib pandu dapat dilaksanakan dengan selamat, tertib dan lancar [4].

Tarif pelayanan pandu merupakan harga jasa dari pelayanan yang diberikan terhadap kapal pada saat akan masuk dan keluar pelabuhan. Tarif pelayanan harus ada keseimbangan antara besaran tarif dengan tingkat pelayanan yang diterima oleh pengguna jasa, meliputi keselamatan, keamanan, kelancaran dan kenyamanan.

Untuk menghitung tarif terlebih dahulu ditentukan berapa besar biaya operasional kapal sebagai dasar dalam menentukan tarif. Komponen biaya operasional kapal berasal dari biaya langsung dan biaya tidak langsung [5].

Penentuan tarif yang terlalu kecil dapat mengakibatkan kerugian bagi perusahaan karena biaya operasional tidak tertutupi, namun tarif yang terlalu tinggi dapat merugikan pengguna jasa [6]. Oleh karena itu dalam menentukan tarif, perusahaan mengambil keputusan berdasarkan biaya yang dikeluarkan. Kesesuaian penentuan tarif dianggap penting demi keseimbangan antara pengguna jasa dan penyedia jasa, sehingga tidak ada pihak yang merasa dirugikan [7]. Jika tarif yang diberlakukan tidak mampu menutupi biaya operasional berarti pihak operator mengalami kerugian. Untuk mengurangi kerugian dapat direspon dengan cara menaikkan tarif jasa pelayanan, namun proses pengajuan usulan tarif ke pemerintah memerlukan pertimbangan yang matang, karena pengguna jasa akan merasa keberatan dengan adanya kenaikan tarif [8]. Formula tarif berdasarkan variable biaya operasional akan sangat memudahkan penetapan tarif, baik statis maupun dinamis [5].

Menurut pengguna jasa bahwa beberapa tahun terakhir mereka tidak mendapatkan pelayanan yang maksimal sesuai dengan tarif yang dibayarkan, seperti keterlambatan penjemputan pandu dan tunda di pintu masuk pelabuhan dan pas pelabuhan yang dianggap terlalu mahal. Sedang di awal tahun 2017 pihak pelabuhan Parepare telah menaikkan tarif jasa pelabuhanan. Pelabuhan Parepare bertekad dan komitmen mengutamakan pelayanan jasa kepelabuhanan dan memberikan kepuasan terhadap pengguna jasa serta berjanji akan segera membenahi masalah-masalah yang terjadi dalam lingkungan pelabuhan. Peningkatan kualitas layanan yang diharapkan juga akan bermanfaat bagi mentalitas penduduk setempat dan dapat membantu mereka dalam kemajuan lainnya [9].

Penelitian ini bertujuan untuk mengetahui kelayakan tarif pelayanan pandu yang berlaku sekarang jika ditinjau dari sisi operator.

\section{Metode Requered Freight Rate (RFR)}

RFR adalah penghasilan dari muatan perunit yang harus dikumpulkan pemilik kapal untuk mendapatkan pengembalian yang equivalen terhadap pembayaran kembali investasinya pada suku bunga yang rendah [2]. Nilai RFR banyak ditentukan oleh produksi jasa transportasi. Kriteria RFR dapat digunakan untuk menilai kelayakan tarif yang berlaku atau sebagai dasar penentuan tarif yang akan ditawarkan kepada pihak pengguna jasa angkutan.

Adapun bentuk umum persamaan RFR adalah sebagai berikut:

$$
R F R=\frac{A A C+(C R F \times I)}{C}
$$

Dimana :

AAC = Biaya rata-rata kapal pertahun

$\mathrm{CRF} \quad=$ Capital Recovery Factor

I $\quad=$ Investasi kapal

C $\quad$ Kapasitas

\section{Hasil dan Pembahasan}

Frekuensi pelayanan pandu diperoleh dengan membagi antara waktu yang tersedia dalam 
setahun dengan pelayanan kapal, dan hasilnya selanjutnya dikali dengan jumlah kapal yang bisa bertambat di pelabuhan. Rata-rata waktu pelayanan pandu pergerakan yaitu 1 jam sedang waktu kapal bertambat yaitu 41 jam. Tonase kapal (GT) diperoleh dari frekuensi pelayanan kapal dikalikan dengan tonase dasar. Tonase dasar merupakan rata-rata total tonase kapal yang masuk ke pelabuhan Parepare.

Hasil perhitungan frekuensi pelayanan pandu dan tonase kapal dari berbagai variasi frekuensi pelayanan (60\% sampai $100 \%)$ dapat dilihat pada Tabel 1. Untuk pelayanan pandu pada frekuensi pelayanan $60 \%$ yaitu sebanyak 122 gerakan/bulan dengan 724.608 GT/bulan atau 1.469 gerakan/tahun dengan 8.695.296 GT/tahun. Sedangkan pada frekuensi pelayanan $100 \%$ yaitu sebanyak 204 gerakan/bulan dengan 1.207.680 GT/bulan atau 2448 gerakan/tahun dengan 14.492.160 GT/tahun.

Tabel 1. Frekuensi pelayanan pandu dan tonase kapal (Hasil analisis data, 2017)

\begin{tabular}{cccccc}
\hline No & $\begin{array}{c}\text { Pelayanan } \\
(\boldsymbol{\%})\end{array}$ & $\begin{array}{c}\text { Pelayanan Kapal (Gerakan) } \\
\text { (Gerakan/Bulan) }\end{array}$ & $\begin{array}{c}\text { GT Kapal } \\
\text { (Gerakan/Tahun) }\end{array}$ & $\begin{array}{c}\text { (GT/bulan) } \\
\text { (GTahun) }\end{array}$ \\
\hline 1 & 60 & 122 & 1.469 & 724.608 & 8.695 .296 \\
2 & 65 & 133 & 1.591 & 784.992 & 9.419 .904 \\
3 & 70 & 143 & 1.714 & 845.376 & 10.144 .512 \\
4 & 75 & 153 & 1.836 & 905.760 & 10.869 .120 \\
5 & 80 & 163 & 1.958 & 966.144 & 11.593 .728 \\
6 & 85 & 173 & 2.081 & 1.026 .528 & 12.318 .336 \\
7 & 90 & 184 & 2.203 & 1.086 .912 & 13.042 .944 \\
8 & 95 & 194 & 2.326 & 1.147 .296 & 13.767 .552 \\
9 & 100 & 204 & 2.448 & 1.207 .680 & 14.492 .160 \\
\hline
\end{tabular}

Sebelum menghitung tarif, terlebih dahulu ditentukan berapa besar biaya opersional kapal sebagai dasar dalam menentukan tarif. Unsurunsur biaya terdiri atas biaya tetap dan biaya variable serta biaya langsung dan tidak langsung. Biaya tetap (Fixed Cost) merupakan biaya yang tidak berubah ketika ada perubahan jasa yang dihasilkan. Biaya tidak tetap (variabel cost) merupakan biaya yang berubah secara proporsional dengan kuantitas volume produksi.

Tabel 2 menunjukkan biaya operasional pelayanan pandu yang terdiri dari biaya tetap sebesar Rp. 574.817.371 dan biaya variabel sebesar Rp. 79.868.104. Jumlah biaya opersaional untuk pelayanan pandu dalam setahun yaitu sebesar Rp. 656.685.475.

Berdasarkan Peraturan Menteri Perhubungan No PM 6 Tahun 2013 bahwa tarif pelayanan pandu diperoleh dari hasil kali antara jumlah biaya operasional pelayanan pandu dalam setahun dengan tingkat keuntungan kemudian dibagi dengan jumlah tonase kapal yang dilayani pandu dalam setahun. Berdasarkan hasil wawancara dengan pihak operator bahwa rata-rata tingkat keuntungan perusahaan yaitu sebesar 3\%. Hasil analisis tarif pelayanan pandu dari berbagai variasi dapat dilihat pada Tabel 3 berikut.

Pada Tabel 3 dapat dilihat bahwa pada frekuensi pelayanan $60 \%$ tarif variabel pelayanan pandu sebesar Rp. 9,46 per GT/gerakan sedangkan tarif tetap sebesar Rp. 403.092 per gerakan. Pada frekuensi pelayanan $100 \%$ tarif variabel sebesar Rp. 5,68 per GT/gerakan sedangkan tarif tetap sebesar Rp. 241.855 per gerakan.

Gambar 1 dan 2 menunjukkan grafik tarif pelayanan pandu. Semakin rendah frekuensi pelayanan maka semakin tinggi tarif dan sebaliknya semakin tinggi frekuensi maka semakin rendah tarif yang harus dibayarkan. 
Tabel 2. Biaya operasional pelayanan pandu (Hasil Olahan Data, 2017)

\begin{tabular}{|c|c|c|c|c|}
\hline No & Jenis Biaya & $\begin{array}{c}\text { Biaya Tetap } \\
(\mathbf{R p})\end{array}$ & $\begin{array}{c}\text { Biaya Variabel } \\
(\mathbf{R p})\end{array}$ & $\begin{array}{c}\text { Total Biaya } \\
\text { (Rp) }\end{array}$ \\
\hline \multirow[t]{14}{*}{1} & Biaya Operasional Langsung & & & \\
\hline & Gaji Pegawai & 85.644 .000 & - & \\
\hline & Tunjangan & 167.020 .800 & - & \\
\hline & Insentif Operasional & - & 43.200 .000 & \\
\hline & Bahan Makanan & 9.120 .000 & & \\
\hline & Bahan Bakar & - & 33.596 .104 & \\
\hline & Bahan Pelumas & - & 3.072 .000 & \\
\hline & Biaya Perlengkapan & 7.504 .000 & - & \\
\hline & Penyusutan kapal pandu & 27.427 .355 & - & \\
\hline & Asuransi kapal pandu & 2.020 .963 & - & \\
\hline & Asuransi Kecelakaan kerja & 1.455 .948 & - & \\
\hline & Pakaian Dinas dan Kerja & 1.000 .000 & - & \\
\hline & Biaya Kesehatan Pegawai Aktif & 14.229 .135 & - & \\
\hline & Total & 315.422 .201 & 79.868 .104 & 395.290 .305 \\
\hline \multirow[t]{10}{*}{2} & Biaya Operasional Tidak Langsung & & & \\
\hline & Gaji pegawai & 167.291.496 & - & \\
\hline & Pemeliharaan peralatan & 658.000 & - & \\
\hline & pemeliharaan Kapal Pandu & 845.000 & - & \\
\hline & Pemeliharaan Kantor Pandu & 2.850 .000 & - & \\
\hline & Biaya Perjalanan Dinas & 34.000 .000 & - & \\
\hline & Biaya Pendidikan \& Latihan & 12.600 .000 & - & \\
\hline & penyusutan jalan \& bangunan & 4.999 .352 & - & \\
\hline & Pemeliharaan jalan \& bangunan & 2.6642 .500 & - & \\
\hline & Total & 249.886 .348 & - & 249.886 .348 \\
\hline \multirow[t]{2}{*}{3} & Biaya Penunjang Operasi & & & \\
\hline & Sumbangan dana pensiun & 9.508 .822 & - & 9.508 .822 \\
\hline \multirow[t]{2}{*}{4} & Biaya Pengelolaan Kantor & 2.000 .000 & - & 2.000 .000 \\
\hline & Total keseluruhan & 574.817 .371 & 79.868 .104 & 656.685 .475 \\
\hline
\end{tabular}

Tabel 3. Tarif pelayanan pandu (Hasil olahan data, 2017)

\begin{tabular}{ccccc}
\hline No & $\begin{array}{c}\text { Frekuensi } \\
(\boldsymbol{\%})\end{array}$ & $\begin{array}{c}\text { Pelayanan Pandu } \\
\text { (Gerakan) }\end{array}$ & $\begin{array}{c}\text { Tarif Variabel } \\
\text { (RP/GT/Gerakan) }\end{array}$ & $\begin{array}{c}\text { Tarif Tetap } \\
\text { (Rp/Gerakan) }\end{array}$ \\
\hline 1 & 60 & 1.469 & 9,46 & 403.092 \\
2 & 65 & 1.591 & 8,73 & 372.085 \\
3 & 70 & 1.714 & 8,11 & 345.508 \\
4 & 75 & 1.836 & 7,57 & 322.474 \\
5 & 80 & 1.958 & 7,10 & 302.319 \\
6 & 85 & 2.081 & 6,68 & 284.536 \\
7 & 90 & 2.203 & 6,31 & 268.728 \\
8 & 95 & 2.326 & 5,98 & 254.585 \\
9 & 100 & 2.448 & 5,68 & 241.855 \\
\hline
\end{tabular}




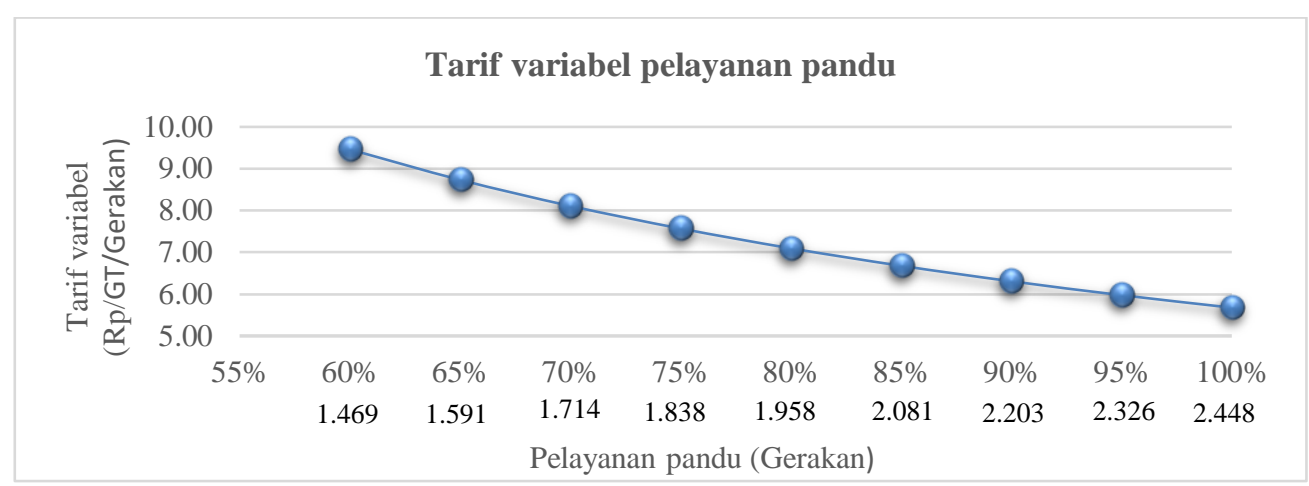

Gambar 1. Grafik tarif variabel pelayanan pandu

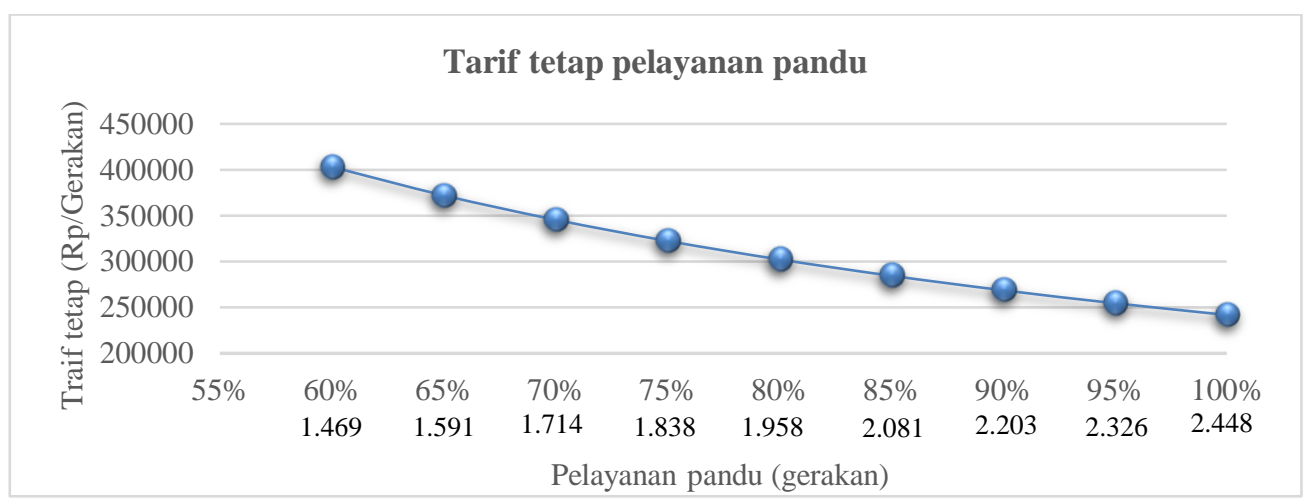

Gambar 2. Grafik tarif tetap pelayanan pandu

RFR digunakan untuk menilai kelayakan tarif yang berlaku atau sebagai dasar penentuan tarif yang akan ditawarkan kepada pihak pengguna jasa. RFR merupakan hasil bagi antara biaya ratarata kapal pertahun dengan kapasitas kapal. Biaya rata-rata pertahun merupakan jumlah dari biaya operasional pelayanan pandu dalam setahun dengan hasil kali antara tingkat suku bunga dengan biaya investasi kapal pandu. Dari hasil perhitungan dengan menggunakan metode RFR diperoleh tarif variabel yang berlaku sekarang lebih besar dibanding hasil perhitungan, sedang tarif tetap yang berlaku sekarang lebih kecil dari hasil perhitungan. Selengkapnya dapat dilihat pada Tabel 4 berikut.

Tabel 4. Tarif minimal pelayanan pandu (Hasil olahan data, 2017)

\begin{tabular}{lrr}
\hline \multicolumn{2}{c}{ Tarif Minimal Pelayanan Pandu } \\
\hline Biaya variabel pelayanan pandu pertahun & $\mathrm{Rp}$ & 79.868 .104 \\
Biaya tetap pelayanan pandu pertahun & $\mathrm{Rp}$ & 574.817 .371 \\
Capital recorvery factor & 0,144027293 \\
Investasi kapal Pandu & $\mathrm{Rp} 288.709 .000$ \\
Tonase Kapal (GT kapal pelayanan 100\%) & 14.492 .160 \\
Frekuensi per tahun & 2448 \\
RFR Tarif Variabel & $\mathrm{Rp} 8,38$ \\
RFR Tarif Tetap & $\mathrm{Rp} 251.797$ \\
\hline
\end{tabular}

Tabel 4 di atas memperlihatkan tarif minimal pelayanan pandu. Dengan tonase kapal (GT) $100 \%$ diperoleh tarif variabel minimal sebesar Rp. 8,38 per GT/gerakan dan tarif tetap sebesar Rp. 251.797 per gerakan. Sedangkan tarif variabel yang berlaku sekarang di pelabuhan Parepare adalah Rp. 76,87 per GT/gerakan dan tarif tetap sebesar Rp. 175.175 per gerakan.

Dari hasil perhitungan dengan menggunakan metode RFR diperoleh tarif variabel yang berlaku 
sekarang lebih besar dibanding hasil perhitungan, sedang tarif tetap yang berlaku sekarang lebih kecil dari hasil perhitungan.

\section{Kesimpulan}

Dari hasil penelitian ini dapat disimpulkan bahwa tarif variabel pelayanan pandu yang berlaku sekarang sudah layak jika ditinjau dari sisi operator. Dengan metode RFR didapatkan tarif minimal yaitu Rp. 8,38 per GT/gerakan lebih kecil dari tarif yang berlaku sekarang yaitu Rp.76,78 per GT/gerakan. Ini berarti bahwa tarif yang berlaku sekarang sudah mampu menutupi biaya operasional. Sedangkan tarif tetap pelayanan pandu yang berlaku sekarang jika ditinjau dari sisi operator dianggap belum layak. Karena dari hasil perhitungan diperoleh tarif minimal Rp. 251.797 per gerakan lebih besar dari tarif yang berlaku sekarang yaitu Rp. 175.175 per gerakan. Ini berarti bahwa tarif tetap yang berlaku sekarang belum mampu menutupi biaya operasional. Tarif ini bisa dinaikkan oleh pihak operator dengan lebih meningkatkan pelayanan kepada pengguna jasa.

\section{Referensi}

[1] Simarmata F. A. (2015). Studi kelayakan investasi pengadaan peralatan PT Pelabuhan Indonesia IV
(Persero) di Makassar (Tesis). Universitas Udayana. Denpasar

[2] Idrus M., Sitepu G., Asri S., Chairrunnisa S. A., \& Djalante H. (2015). Identification of role of feeder, collecting and local ports in Sulawesi corridor in supporting the national connectivity. International Journal of Engineering and Science Applications, 2406-9833.

[3] Saleh F. E. (2011). Analisis pengaruh kualitas layanan terhadap kepuasan pelanggan (studi di PT Pelindo III cab. Tg. Emas Semarang). (Skripsi). Semarang. Universitas Diponegoro.

[4] Kusuma D. G., Pitana T., \& Gurning S. O. R. (2013). Aplikasi data Automatic Identification System (AIS) dan shipping database untuk memonitor pelayanan kapal di pelabuhan berbasis internet secara real time. Surabaya. Institut Teknologi Sepuluh Nopember.

[5] Sitepu G., Muhammad. H., \& Muslihati. (2011). Formulasi tarif angkutan penyeberangan perintis. Makassar. Teknik Perkapalan. Universitas Hasanuddin

[6] Djalante H. A., Farianto., Wijaya H. (2011). Analisa kelayakan tarif kapal ferry Ro-Ro KMP. AwuAwu lintasan Barru-Batulicin, Prosiding, Makassar.

[7] Afriyanah R. S. (2014). Perhitungan biaya angkutan penyeberangan lintas Tarakan-Toli Toli. Jurnal Penelitian Transportasi Darat, $16: 2$.

[8] Karles H., Santoso D. (2013). Analisis komponen biaya dan tarif angkutan penyeberangan dengan simulasi model dinamis pada angkutan lintasan Sibolga -Teluk Dalam PT ASDP Indonesia Ferry (persero). Jurnal MIX, 2: 160-174.

[9] Zlatoudis E. A. (2016). Urbans sea transportation in grece, the case of skiathos. Transportation Research Procedia, 24:418-424 